CARLOS MOLINA

UNIVERSIDAD DE ESSEX

\title{
Fernando Gamboa y su particular versión de México
}

$\mathrm{L}$

A NOCHE EN QUE SE PRESENTÓ UN LIBRO conmemorativo de los cincuenta años como museógrafo de Fernando Gamboa, el homenajeado seografía" . Cuando se intenta hacer un estudio sobre el trabajo de Fernando Gamboa, uno se topa con la mitología del "Jefe", merecidas loas de quienes trabajaron con él y, acaso, con explicaciones de su método como una cualidad propia y misteriosa. Es sabido que su discurso curatorial se volvió canónico en México a partir de I950, pero nada más. En resumen, no hay nada útil para el análisis de una práctica en la que se intersecan narrativa histórica, práctica museográfica, gramática del espacio y preocupaciones tanto estéticas como políticas. Si la naturaleza en sí de las exposiciones es efímera, el modo Gamboa de representar lo mexicano a través de su arte siguió siendo influyente mucho tiempo después de la muerte del museógrafo. Todavía en los años 2000 y 2002, dos exposiciones llevadas a cabo en Europa acusan la impronta de Gamboa. ${ }^{2}$

I. La frase es de Vicente Rojo y fue recogida en Fernando Gamboa. A sus so años como museógrafo y difusor de la cultura, México, Universidad Autónoma Metropolitana-Iztapalapa, Secretaría General de Desarrollo Social, 1985, p. I7.

2. En la exposición internacional de Hannover 200o, México Eterno: Arte y Permanencia, las estrategias utilizadas en el pabellón mexicano y durante la muestra Aztecs (Londres, 2002) acusan la impronta de Gamboa en lo espacial y en el articulado histórico de los conjuntos. Eduardo Matos Moctezuma y Felipe Solís, "Los aztecas en Londres", Museos de México y el Mundo, núm. I, vol. I, primavera de 2004, México, Consejo Nacional para la Cultura y las 
Fernando Gamboa implementaba un entramado que en el fondo planteaba un continuum histórico del arte, un espíritu nacional en México, a través de varios siglos. En la forma, ponía énfasis en el conjunto, no obstante articular la muestra a partir de piezas específicas, obras maestras que servían como prueba de un argumento más amplio. ${ }^{3}$ Estas notas — parte de una tesis de doctorado en curso- intentan descubrir qué clase de historia contaban las exposiciones de arte mexicano hechas a mediados del siglo xx y de qué modo eran llevadas a cabo en cada sitio donde se presentaron.

Intentaré, en lo sucesivo, comparar el trabajo de "museógrafo", palabra que Gamboa empleaba para describir su quehacer, con el de Miguel Covarrubias, quien también se desarrolló en ese campo. Encuentro en Gamboa, al menos, un tropo tal que lo suyo es curatorial incluso antes de haberse desarrollado la distinción entre ambos oficios —el de museógrafo y el de curadorcomo ocurre en nuestros días. Fernando Gamboa estructuraba la exhibición de piezas en etapas tales que no estaban a discusión, constituyendo una perspectiva "del desarrollo artístico y un panorama de nuestra historia tan completo como sea posible". ${ }^{4}$ Así describe Gamboa el objetivo de su muestra en la introducción al folleto que acompañaba la exposición que viajó por Europa entre 1951 y 1953 (Arte Mexicano, Antiguo y Moderno). En I950, nombrado comisario para la Bienal de Venecia, Gamboa ya había hecho un ensayo para definir lo mexicano y sus momentos en el tiempo. Cuatro etapas históricas superpuestas a una sola idea artística: lo mexicano representado en la época prehispánica, durante la colonia, en el México moderno y en la época contemporánea a Gamboa mismo. El añadido de artes populares y folclor no hacía sino acentuar el supuesto nacionalista desde el apunte sociológico. Ya

Artes/Instituto Nacional de Antropología e Historia/Instituto Nacional de Bellas Artes, pp. 60-69, y en La Jornada, Is de enero de 2000, www.jornada.unam.mx/200o/eneoo/ oooirs/cul3.html, "Treinta siglos de arte mexicano en París", nota de Mónica Mateos, URL accesado el I de septiembre de 2004, I7:45, GMT.

3. Mariana Frenk-Westheim comentó el día del homenaje que Gamboa establecía perfecta consonancia entre el conjunto y aquellas piezas que aislaba estéticamente y eran superiores a las otras. Fernando Gamboa, embajador del arte mexicano, México, Consejo Nacional para la Cultura y las Artes, I991, y Homenaje a Fernando Gamboa. Pintura mexicana, 1950-I980, México, Instituto Nacional de Bellas Artes/DDF/IBM, I995.

4. Fernando Gamboa, "Introducción", en Mexican Art from I50o b.C. to the Present Day: Illustrated Supplement to the Catalogue of an Exhibition at the Tate Gallery, London, 4 March to 26 April I953, Londres, Arts Council of Great Britain, I953, p. 64. 
Teresa del Conde ha llamado la atención sobre el hecho de que semejante compendio de lo mexicano y su arte tiene como antecedente directo el trabajo museográfico y curatorial llevado a cabo por Miguel Chamaco Covarrubias en el Museo de Arte Moderno de Nueva York en 1940.5 Veinte Siglos de Arte Mexicano tenía cuatro secciones: lo prehispánico, lo colonial, lo folclórico y la modernidad. ${ }^{6}$ Gamboa explicaría después, en una conferencia que escribió para la Bienal de Venecia en mayo de 1950, que "tras tres siglos de dominación colonial española, y en mitad del siglo diecinueve, México comenzó a recobrar su propia expresión plástica". ${ }^{7}$ Ambas exposiciones proponen cuatro etapas; lo que México "recobra" hacia 1950 es aquello que fue "dominado" en la colonia y que constituye lo esencial del arte mexicano.

Otro rasgo en común de ambas exhibiciones, la de Covarrubias en 1940 y la de Gamboa entre 1950 y 1953, es que una y otra cumplían funciones diplomáticas. No sólo fueron presupuestadas y promovidas por el Estado mexicano, que veía con buenos ojos la mexicanidad representada, la nación sobre la que su gobierno se legitima, sino que eran un imperativo en el ámbito panamericano. Fue la Secretaría de Relaciones Exteriores la que canalizó recursos hacia las muestras, sirviendo además como nexo institucional entre los involucrados y las entidades extranjeras pertinentes. La cancillería mexicana debía aprobar previamente todo cuanto Gamboa propusiera. El catálogo de la exposición que primero viajó a Estocolmo, luego a París y finalmente a Londres habla del "orgullo consciente de un pueblo, esfuerzo por revelar un origen antiguo y exponer nuestra vida espiritual". ${ }^{8} \mathrm{El}$ arte era considerado entonces como un "valor espiritual" y suponía una circunstancia común a toda la humanidad, que podía ser ilustrada por sus logros en la plástica y su patrimonio cultural. Es decir, una vez que los objetos mostrados por una nación a las otras son aceptados y aclamados como de naturaleza artística, son ungidos en el museo y reconocidos universalmente dada esa misma virtud intrínseca que parecen tener. Los países han logrado así elevarse al mismo status y entablar un diálogo civilizado. ${ }^{9}$

5. Teresa del Conde, "Recordando a Gamboa”, en La Jornada, núm. 5680, vol. XVI, 4 de julio de 2000, "Opinión”, www.jornada.unam.mx/2000/juloo/ooo704/conde.html.

6. Miguel Covarrubias, en Twenty Centuries of Mexican Art, Nueva York, Museo de Arte Moderno de Nueva York, 1940-194I, p. Io.

7. Documento foliado 48TT, Archivo Fernando Gamboa, ocho páginas mecanografiadas.

8. Mexican Art from I5oo b.C., op. cit., p. 64.

9. Carol Duncan, "Art Museums and the Ritual of Citizenship", Exhibiting Cultures. The 
Durante el siglo XIx, la construcción de la identidad nacional se había hecho a partir de la consolidación de instituciones, del reclamo de hegemonía frente a intereses extranjeros y mediante la escritura de una historia patria. Es en esta última modalidad como la conservación del patrimonio artístico sirve de ilustración al relato nacional propuesto y resulta el vehículo idóneo para su transmisión al pueblo mexicano. Poco después de la Independencia, el primer Congreso decreta la formación de un museo nacional. ${ }^{\text {IO }}$ Los objetos que conformarían dicha colección habrían de ser de dos clases fundamentalmente: vestigios arqueológicos del supuesto y glorioso pasado nacional y un conjunto de artes plásticas equiparable a la de los países considerados más civilizados por entonces. La estrategia siguió siendo la misma a lo largo de todo el siglo xx. Sin embargo, cada uno de estos objetos presentaba, entonces y ahora, una serie de polémicos argumentos sobre el México actual y su representación. La identidad que se inventaba, la que todos los mexicanos, elites gobernantes, artistas e intelectuales elucidaban poco a poco, era puesta en escena y explicada cada vez que un museo nacional se montaba u ordenaba su existencia conforme a ciertos presupuestos. ${ }^{\text {II }}$ Si miramos la curaduría de tales exposiciones, o su proyecto al menos, estamos observando una sintaxis de los eventos que supuestamente formaron la nación mexicana, que los ciudadanos, o su gobierno, decidieron mostrar como patrimonio artístico. Tal identidad se forma a partir de la inclusión de México como entidad nacional en la historia universal. Para los mexicanos mismos, la articulación de tal historia supone etapas sucesivas y necesarias: un pasado prehispánico, si bien nativo y remoto, aún vigente en la población indígena del país; la con-

Poetics and Politics of Museum Display, Washington-Londres, Levine-Smithsonian Institution Press, I991, pp. 88-93.

Io. Isidro Rafael Gondra y Carlos María de Bustamante se cuentan entre los firmantes del Acta de Independencia. Ellos eran también miembros de la junta encargada de llevar a cabo el proyecto de un museo nacional el is de junio de i826; citado por Luisa F. Rico Mansard, "Los museos de México y su función educativa (I790-I9IO)", tesis doctoral de historia, México, Universidad Nacional Autónoma de México-Facultad de Filosofía y Letras, 1996. "Introducción” y "Anexo documental I".

II. Para examinar la noción de "tradición inventada", véase Hobsbawm y Ranger (eds.), Inventing Tradition, Cambridge University Press, 1983, passim; para conocer un análisis del mismo proceso en los sistemas de educación básica, véase Yasemin Soysal, "World Expansion of Mass Education, I870-1980", en Sociology of Education, vol. 65, abril de 1992, pp. I28-I49. 
quista u otros momentos de amenaza por parte de algún enemigo extranjero; su posterior derrota y el fortalecimiento consecuente del supuesto nacional; finalmente, tendría que haber una evaluación de la realidad del México presente a través del arte. Ésos son los eventos constituyentes de la narrativa de la mexicanidad oficial. A menudo esta sucesión de épocas se vio como natural, el relato subsiste sin ser impugnado por su coherencia y potencial como modelo cohesionante para la población. Semejante articulación es entonces promovida y aceptada; son las fases simbólicas de nacimiento, resistencia y consolidación de la patria. El mismo esquema ha sido llamado por Mauricio Tenorio Trillo como fases de "independencia, libertad y paz" . ${ }^{22}$ Cada Estado emergente no hegemónico durante los siglos XIX y Xx celebra y consagra tales momentos para legitimar, escribir y enseñar su historia. ${ }^{13}$ Mitos fundacionales y piedras de toque para la identidad, que hallan siempre en el arte la ilustración precisa y suficiente usada como evidencia para un proceso de autoinvención y legitimación histórica.

Las dos exposiciones hasta ahora consideradas, la de Nueva York en 1940 y la que recorrió Europa entre 1950 y 1953, son similares en contenido. Difieren, no obstante, en cuanto a su forma museográfica. Si bien comparten la estructura narrativa oficial de la historia mexicana y la tácita aceptación ideológica de un gran arte universal, son distintas si se miran las estrategias de sus

I2. El texto original del Acta de Independencia de México habla de un "salir" de la nación. "Acta de Independencia del Imperio Mexicano, pronunciada por su junta soberana, congregada en la Capital de el, en 28 de setiembre de I82I. La Nación Mexicana, que por trescientos años, ni ha tenido voluntad propia, ni libre uso de la voz, sale hoy de la opresión en que ha vivido [...] esta solemne declaración, hecha en la capital del imperio a veintiocho de setiembre del año mil ochocientos veintiuno, primero de la independencia mexicana." Documento 52.I66.I9 Museo y Colección Fondo Dick S. Ramsay, Brooklyn Museum of Art, Nueva York, EUA (impreso, tinta sobre papel). En mi tesis doctoral desarrollo las implicaciones de ese esquema para narrar la historia de México en el museo. He llamado sus etapas sucesivas y necesarias: nacimiento, resistencia y consolidación. De tal manera que aquello que "resiste" durante la conquista, el asalto al castillo de Chapultepec o la intervención francesa había "nacido" en épocas prehispánicas y promete "consolidarse" en el futuro cercano de quien emplea el esquema, en este caso Gondra, Bustamante o Gamboa. Compárese con el esquema empleado por Mauricio Tenorio Trillo, Mexico at the World's Fairs. Crafting a Modern Nation, Berkeley-Londres, University of California Press, 1996, passim.

13. Theda Skocpol, States and Social Revolution; a Comparative Study of France, Russia and China, Cambridge University Press, 1979, p. XXIII. Perry Anderson, Lineages of the Absolutist State, Verso Books, 1994 . 
curadores para montarlas; mientras que la de Covarrubias aparece como etnográfica y contextual, Gamboa emplea estrategias que aíslan a los objetos, estetizándolos. Un primer apunte para apreciar esta diferencia puede verse en las fotografías de los primeros montajes documentables de ambos autores: la colaboración de Miguel Covarrubias para el Pabellón Mexicano en Sevilla, en 1929, y la exposición de grabados de José Guadalupe Posada presentada por Fernando Gamboa en el Instituto de Arte de Chicago en 1944 (del I3 de abril al I4 de mayo de 1944). La caracterización de estilos museográficos y los rasgos curatoriales de cada montaje —enfoque "etnográfico" y regionalista el de Covarrubias, aproximación "estetizante" y universal la de Gamboatienen también resonancia en la biografía de ambos personajes. Mientras Covarrubias era un entusiasta de la antropología que con el tiempo se profesionalizó, Gamboa, funcionario cultural de alto rango, fue formado como grabador y arquitecto. Los dos curadores parecen considerar cuatro ámbitos distintos a partir de los cuales la imagen de México sería aprehendida. Ello implica también una jerarquía para su percepción. El arte es el primero de esos ámbitos, compuesto por objetos que caen en la descripción amplia de pintura, escultura, artes menores y artesanía. En segundo lugar quedaba la arqueología, de donde algunos especímenes fueron elevados a la categoría de artísticos, de modo tal que muchos otros objetos arqueológicos aparecían como genuina utilería decorativa de puestas en escena para una mexicanidad remota y gloriosa (solían ser copias, moldes, escultura menor y monumentos varios). El tercer orden o ámbito es instrumental para todas y cada una de las exposiciones, pero es también de naturaleza efímera y su sola función es la de ofrecer un techo al arte y la arqueología; se trata de las soluciones arquitectónicas elegidas para cada pabellón o las adaptaciones hechas al espacio del museo donde la exposición se alojaba. Finalmente, estas exposiciones, conforme a una práctica rara vez considerada en sí misma, eran acompañadas por fotografías que usualmente servían para ilustrar el contexto original de los objetos exhibidos o describir los usos y costumbres de México. Si bien hay un claro uso de la fotografía como recurso para el comentario sociológico, no hay evidencia de que alguna fotografía se expusiera sin más, como "arte". También la fotografía se usó por su capacidad meramente informativa, para ilustrar folletería y propaganda de las exposiciones o las inauguraciones o los públicos asistentes (fig. I).

Debió de ser en 1928, al volver a México de su exitosa aventura haciendo caricaturas para Vanity Fair, cuando Miguel Covarrubias conoció a Fernan- 

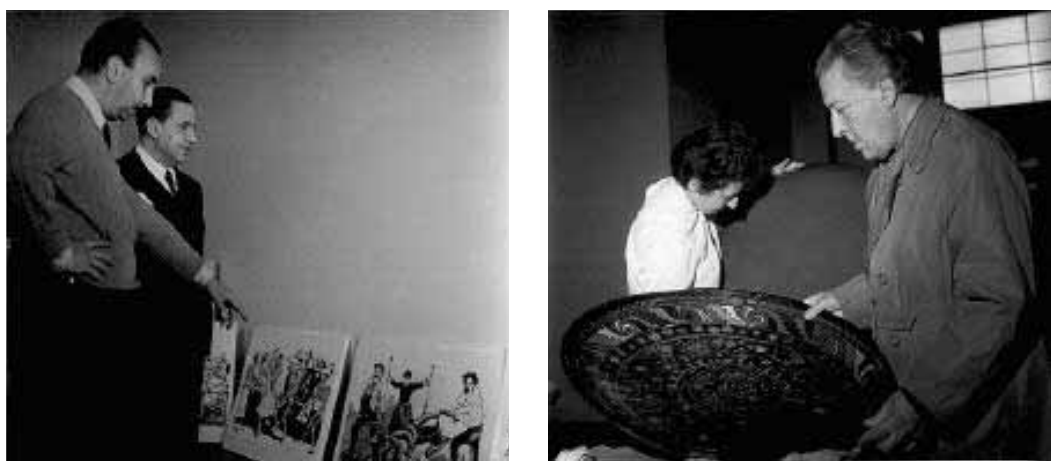

Ia. A la izquierda, el curador Fernando Gamboa montando la exposición de París, I952, Archivo Fernando Gamboa.

Ib. A la derecha, André Breton inspecciona obras de arte popular mexicano en la exposición de Gamboa, Archivo Fernando Gamboa.

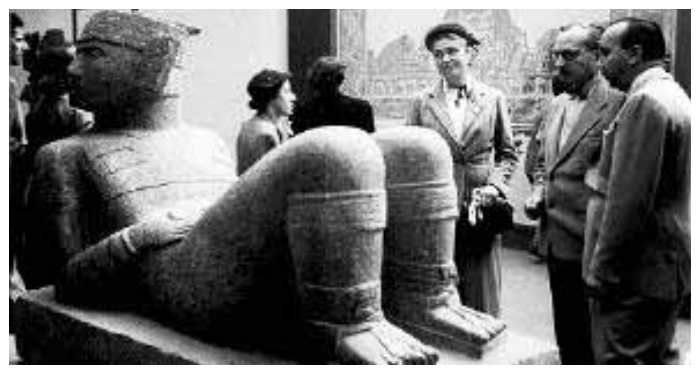

Ic. París, 1952, Archivo Fernando Gamboa.

do Gamboa. ${ }^{\mathrm{I4}}$ También entonces debieron entrar ambos en contacto con René d'Harnoncourt, quien para entonces buscaba proveer a Fred Davis de artesanías y artes populares para su tienda y galería. Ellos le aconsejaron qué y dónde comprar. D'Harnoncourt trabajaba en su primera muestra para la

I4. Covarrubias vivía con Rufino Tamayo y ambos gozaron de la hospitalidad de José Juan Tablada en el 892I Ursula Place de Forest Hills, Nueva York. Véase Guillermo Sheridan, "Carta iracunda" del 27 de septiembre de 1927, de J.J. Tablada para Genaro Estrada en Vuelta, núm. 157 , diciembre de 1989 , pp. 44-46. Gamboa recién terminaba su participación en las 
American Federation of Arts, que se inauguraría en Nueva York en diciembre de 1930. Se suponía que sería una combinación de piezas modernas y "primitivas". ${ }^{15}$ Las colecciones que integraron esa exposición fueron las del propio D'Harnoncourt, William Spratling, Anita Brenner, Jorge Enciso y el ex embajador Dwight D. Morrow. Covarrubias prestó once piezas de su colección personal y D’Harnoncourt usó cinco de las pinturas de Miguel para la sección de pintura moderna. Covarrubias y D'Harnoncourt volvieron a Nueva York, mientras que Gamboa se quedó en México pintando murales para los Talleres Gráficos de la Nación junto a Pablo O’Higgins, Leopoldo Méndez y Alfredo Zalce. ${ }^{16}$ Muy involucrado en la vida política y artística del momento, Gamboa presidió durante un periodo la Liga de Escritores y Artistas Revolucionarios (LEAR). Para mayo de 1937, Covarrubias participaría en la Novena Bienal del Museo de Brooklyn, exposición de más de 200 obras, algunas de ellas piezas prehispánicas dibujadas y escogidas por él mismo. Formó, además, parte del jurado que seleccionaría a Emilio Amero, Jean Charlot, Carlos Mérida, Carlos Orozco Romero, José Clemente Orozco, Diego Rivera, David Alfaro Siqueiros, Rufino Tamayo y otros pintores menos conocidos. Es entonces cuando Nueva York mira a una pléyade de mexicanos que supuestamente representan el largo continuum de la mexicanidad, en medio de un revival indigenista en toda América. Miguel Covarrubias acepta una invitación del G. Macy Club de ediciones limitadas en 1940 para ilustrar la traducción de la obra de Bernal Díaz del Castillo. ${ }^{17}$ Alfred Barr lo insta a unirse a D'Harnoncourt y curar la exposición que se inauguraría en el $\mathrm{Mu}$ seo de Arte Moderno de Nueva York en mayo siguiente. Nelson Rockefeller, entonces director de ese establecimiento, anunció que la muestra "cubriría el registro entero del arte mexicano, desde tiempos arcaicos, a través del perio-

misiones culturales, un ejercicio plenamente documentado por él mismo en su Archivo de la calle de Tolstoi i4, México, D.F. Los documentos se hallan en fólder rotulado "Secretaría de Educación Pública", folios FG-SEPI al FG-SEP63, y todos los reportes datan de I930 y I932, con excepción del que concierne a sí mismo. Gamboa conservaba además — firmado por el autor para sí- el libro editado por Salvador Novo, Las misiones culturales en Ig27 (Las escuelas normales rurales), México, Secretaría de Educación Pública, 1928, documento FGI248.

I5. Adriana Williams, Covarrubias, Austin, Texas University Press, I994, pp. I3-I6.

I6. Raquel Tibol, Gráficas y geográficas, México, Casa Juan Pablos/Secretaría de Cultura del Gobierno del Distrito Federal ( $\mathrm{I}^{\mathrm{a}}$ ed. I987), 2002, p. 303.

17. Bernal Díaz del Castillo, The True History of the Conquest of Mexico (ilustrado por Miguel Covarrubias), G. Macy Editions, 194I. 
do de grandes culturas indias, la colonización española, e incluyendo material de la actualidad" ${ }^{18}$ Es en el marco de esta exhibición donde se insistiría en la política de colaboración panamericana que el arte y su promoción suponen. ${ }^{19}$ El comité organizador en funciones en Nueva York en 1940 estaba compuesto de académicos y artistas por igual: Pablo Martínez del Río, Gabriel Fernández Ledesma, Justino Fernández, Miguel Covarrubias, Alfonso Caso y Roberto Montenegro. Daniel Rubín de la Borbolla, un académico mexicano de la antropología, consideró la elección de colaboradores hecha por Barr como brillante y atinada. ${ }^{20}$ Tres años más tarde, Fernando Gamboa, Daniel Rubín de la Borbolla y Miguel Covarrubias crearían la carrera de museografía en la Escuela de Antropología de la ciudad de México. ${ }^{21}$

El is de agosto de 1938, Gonzalo Vázquez Vela, secretario de Educación Pública durante la presidencia de Lázaro Cárdenas, aprobó un documento elaborado por Celestino Gorostiza —entonces jefe del Departamento de Bellas Artes - titulado Reglamento Interno para los Museos Oficiales de Artes Plásticas". ${ }^{22}$ En él se consideraban a las galerías de pintura y escultura del Palacio de Bellas Artes, la Escuela de Artes Plásticas y el Museo de Artes Populares. ${ }^{23}$ El documento pone especial énfasis en que el "objeto" de dichos museos es "constituir el patrimonio artístico del pueblo mexicano" y que por ello deben estar abiertos al público. Incluye también una descripción de la jerarquía institucional y sus funciones. Indica además que sólo podrán ser directores de museo "individuos entrenados como técnicos en artes plásticas y conocedores de los problemas de la museografía". Al margen, alguna secretaria anotó con lápiz, sobre la copia al carbón: "Sr. Gamboa”; el documento le había sido remitido para informarlo y ponerlo al tanto de la normatividad;

I8. Cuaderno de notas número 45, nota II, Archivos Rockefeller; como se cita en Adriana Williams, op. cit.

I9. Nelson Rockefeller, jr., s.d., documento FGI, Archivo Fernando Gamboa.

20. Daniel Rubín de la Borbolla, México. Monumentos históricos y arqueológicos, México, edición del autor, 1953 , introducción, passim.

2I. Hay un proyecto para el certificado técnico en museografía en el Archivo Fernando Gamboa, documento FG44, p. I4. Información confirmada mediante una entrevista con Alfonso Soto Soria, alumno de aquella carrera el I2 de agosto de 2003 (archivo sonoro eAss0308I2.wav).

22. Documentos con el folio FG7 al FGio, Archivo Fernando Gamboa.

23. Ibidem; el artículo 24 promete una definición de lo que constituye el arte popular y de los objetos que responderían a ella. 
ordenaba que el director participara en todo comité institucional, decidiera sobre el presupuesto y evaluara las muestras y su despliegue espacial, observando siempre la disciplina del personal. Gerente, creador, personalidad indiscutible e indiscutida, rasgos todos que se dice Gamboa no perdió nunca. Escrito mucho antes de ser funcionario, resulta el primer ordenamiento institucional que organiza la vida de un museo como Gamboa los conoce. Tal es el lugar que ocupaba en su archivo personal; ello indica su propia cronología.

Ése sería el puesto que se asignaría a Gamboa a su regreso de España, en 1939. Responsable de la exposición Un Siglo de Grabado Político Mexicano, Fernando Gamboa está entre quienes forman parte del contingente mexicano que asiste al Segundo Congreso de Escritores por la Defensa de la Cultura (también referido en la época como Congreso Internacional de Escritores Anti-Fascistas) en París. La invitación, firmada por Pablo Neruda, llega al local de la LEAR fechada el 9 de abril de 1937 . Pero, a diferencia de sus compañeros, ${ }^{24}$ el 8 de junio de 1937 , acreditado como corresponsal del periódico El Nacional, órgano del Estado mexicano, Gamboa viaja ya con reconocimiento y en misión oficial del gobierno de su país (fig. 2). Gamboa probaría ser de mucha ayuda en los años sucesivos para la política exterior del presidente Cárdenas y la de regímenes sucesivos, en la función diplomática que entonces cumplía el arte. Al frente de la delegación mexicana que viajó a Nueva York en 1940 estaba el secretario de Relaciones Exteriores, Eduardo Hay. Gamboa colaboró a su llegada a Madrid con Hay, luego de que 807 personas fueron protegidas en la embajada mexicana después del 29 de marzo de $1937 .{ }^{25}$ En el archivo de Fernando Gamboa se conservan listas completas de los pasajeros que venían a bordo del Sinaia y otros barcos en 1939, además del periódico elaborado a bordo, que incluía crónicas de los eventos culturales ahí representados, fotografías que después difundió la prensa mundial y un diario novelado por Gamboa mismo (sospecho que escrito a posteriori);

24. Viajaron Octavio Paz, Silvestre Revueltas, Juan de la Cabada, José Mancisidor, Carlos Pellicer y José Chávez Morado, entre otros; a su llegada se encontrarían con David A. Siquieros, Tina Modotti y Angélica Arenal, quienes servían a las órdenes de Carlos Contreras -Vittorio Vidali- en el $5^{\circ}$ Regimiento.

25. "Asilados españoles en la embajada de México en Madrid", Memoria de la Secretaría de Relaciones Exteriores, periodos 1934-1935, 1936-1937 y 1937-1938, presentada al H. Congreso de la Unión por E. Hay, secretario del ramo, Departamento Autónomo de Prensa y Publicidad, pp. 35-36; como se cita en José A. Matesanz Ibáñez (comp.), México y la República española. Antología de documentos, I931-1977, México, Centro Republicano Español de México, 1978. 
2. Archivo Fernando Gamboa.

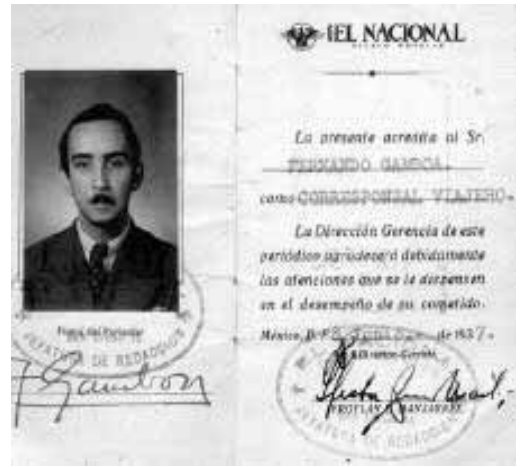

sigue un guión de eventos, sobre el que "tacha" lo que ya lleva escrito, algunas páginas a mano, otras ya mecanografiadas). ${ }^{26}$ Eduardo Hay era además viejo conocido de José Juan Tablada, Roberto Montenegro y Gabriel Fernández Ledesma — colaboradores y amigos de Gamboa- desde hacía muchos años. ${ }^{27}$ No hay modo de documentar gráficamente la exposición de grabado que la LEAR juntó y Gamboa montó en Valencia, Barcelona y Madrid, pero lo mismo ésta que la de Posada en 1944 sirven al propósito claro de unir el presente de México en el siglo xx con tradiciones no académicas y la imaginería popular de épocas anteriores, al tiempo que hacen un manifiesto explícito de la situación política mundial que forma su contexto.

Otra de las personalidades intelectuales que Gamboa conoció en España en aquel 1937 fue Gisèle Freund, quien a su vez lo presentó con el fotógrafo y reportero norteamericano Robert Capa. La teórica de la sociología y fotógrafa profesional había salido de Alemania en 1933 y, tras presentar una tesis de doctorado en la Sorbona, viajó a Madrid. ${ }^{28} \mathrm{Al}$ término de la segunda guerra

26. Diario FGLEAR 239-279; 37 hojas mecanografiadas, cuatro manuscritas. Escrito en primera persona. Especialmente el relato de la invitación enviada por Neruda y la composición del representativo mexicano difieren radicalmente de la misma historia platicada por Octavio Paz; veáse Octavio Paz, Obras completas, tomo 9: Ideas y costumbres I. La letra y el cetro, BarcelonaMéxico, Círculo de Lectores, Fondo de Cultura Económica, 1995, p. I5 y ss.

27. Así lo prueba la fotografía hallada en www.tablada.unam.mx/archivo/fotograf/notas/ iII4a-30.html, itemII4, b/n, IO × 8", URL accesado el I4 de julio de 2004, I7:35, GMT.

28. Esta investigación fue conocida mundialmente sólo hasta 1976; la traducción al inglés es de 1980 . Pero las ideas respecto a la sociología y la fotografía se habían desarrollado 45 o 50 


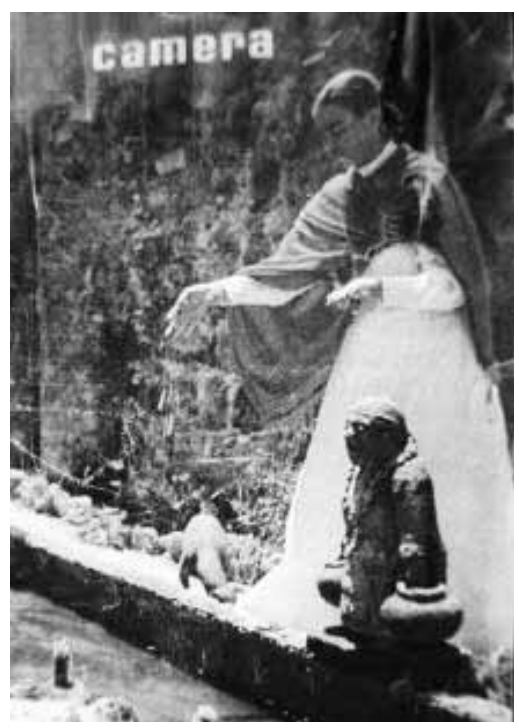

3. Camera, núm. 2, febrero de 1954, C. J. Bucher Ltd., Lucerna, Suiza, Archivo Fernando Gamboa.

mundial, Gisèle Freund decidió mudarse a México, por invitación de Diego Rivera y Fernando Gamboa. Colaboró en al menos dos publicaciones extranjeras mientras estuvo en la ciudad de México, en 1949. La fotografía de portada del número 2 de la revista Camera así lo acredita; en la página siguiente hay una fotografía que muestra a Frida Kahlo de pie tirando migajas de pan a los patos en el estanque de su casa en Coyoacán, cuya autora es Freund (fig. 3). ${ }^{29}$ La revista fue hallada en el archivo de Fernando Gamboa con una nota autógrafa de "F" (¿Fernando, Frida o Freund?). A pesar de su fascinación por México, Gisèle Freund prefiere regresar en 195I a Europa y vuelve a París, donde Robert Capa le pide trabajar para la recién fundada Agencia

años atrás. Gisèle Freund, La fotografía como documento social (Photographie und Gesellschaft, Berlín, 1969), Barcelona, Gustavo Gili, 1976.

29. Camera, núm. 2, febrero de 1954, C.J. Bucher Ltd., Lucerna, Suiza, s.d., Archivo FG, pp. 50-54. La fotografía se publica como parte de un artículo titulado "Artiste... Artisan...?", donde es reconocida como "Attaché of the Mission at the Musée de l'Homme and at the Mexican Artistic Mission in Europe, reporter for Magnum". 


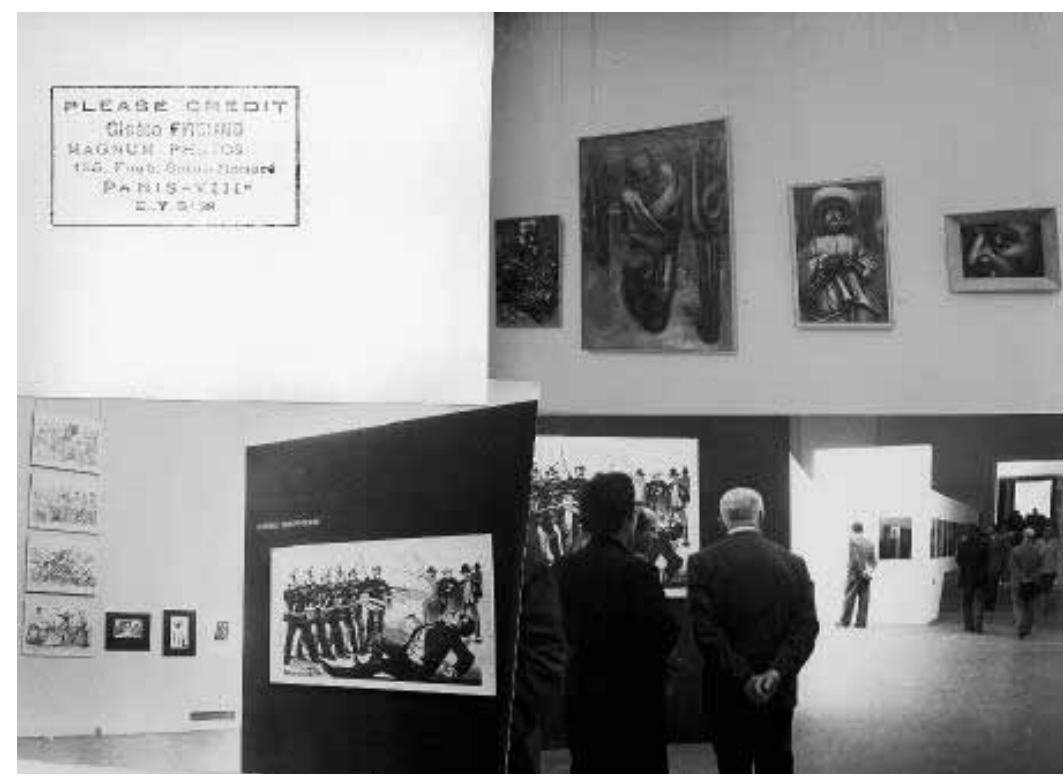

4. Sin catalogar, París, I952, Archivo Fernando Gamboa. Arriba a la izquierda se ve el crédito de Gisèle Freund.

Magnum. ${ }^{30}$ Cuando la exposición de Arte Mexicano, Antiguo y Moderno va de Estocolmo a París, Fernando Gamboa contrata a la Agencia Magnum y a Gisèle Freund para hacer todas las fotografías que necesita. Tanto las que documentan el montaje como las que hacen crónica del evento inaugural o retratan al público asistente tienen estampada al reverso la siguiente leyenda: "Crédit Gisèle Freund Magnum photos I25 Saint Honoré Paris 8ème arrondissement" (figs. 2 y 4).

Además de sustentar el artilugio nacionalista, Fernando Gamboa tiene otra preocupación observable en su quehacer museográfico: no la inclusión en términos cuantitativos, sino el status o calidad mismos que concederá a la

30. El siguiente sitio mantiene una página de internet con transcripciones de notas en homenaje a Gisèle Freund, aparecidas en los periódicos London Times y New York Times el I ${ }^{\circ}$ de abril de 2000, tras la muerte de la fotógrafa el día anterior (www.temple.edu/photo/ photographers/gisele/gisele.html, URL accesado el 2 de octubre de 2004, I5:I2, GMT). 
fotografía en sus montajes. Durante la Bienal de Venecia se consolida el mito de los "tres grandes" y el "cuarto disidente": Rivera, Siqueiros, Orozco y Tamayo son la bandera del arte mexicano contemporáneo en el mundo. Ellos representan la construcción que emparentó a mexicanos de uno y varios siglos, lo connacional se reconoce en los rasgos o el orgullo indígenas, se informa así al mundo de "nuestras" glorias. La característica fundamental de aquellas pinturas era que, siendo formalmente diversas, son similares en su búsqueda; intentan escapar de la interpretación usual desde la bidimensionalidad agregando materialidad al óleo con polvo de mármol o experimentando con la piroxilina. En el fondo, dado su contenido, se les identifica en la figuración del tema indio o en la representación idiosincrática de lo mexicano. Fernando Gamboa había sido nombrado jefe de Artes Plásticas, y luego director del recientemente fundado Museo Nacional de Artes Plásticas. ${ }^{3 \mathrm{I}}$

Atrapado entre la diferenciación estética y la toma de decisiones políticas, Gamboa parece preocupado por el impacto social de lo que él y sus exposiciones proponen en el extranjero como representativo de la realidad mexicana. La preocupación sociologizante sobre la imagen y su referente se agudiza con la cercanía de Gisèle Freund. Considero que es la alemana quien sugiere el uso extensivo de la fotografía para documentar la vida diaria de aquel universo que las obras de arte refieren. Coincide también 1952 y la estancia de Gamboa en París con un cambio radical en la cantidad y calidad de las fotografías empleadas. El argumento expuesto por Freund es simple: desde su invención en el siglo XIX, y tras su popularización en el siglo xx, la fotografía estaba tan directamente relacionada con la vida diaria y era tan aceptada, más allá de cualquier barrera socioeconómica, que no hay modo ya de separar la práctica de su representación. Es decir, la visión de quienes fotografían y el potencial político de la lectura de aquellas imágenes, en su contexto y después como documentos históricos, son incontestables. ${ }^{32}$ En 1946 Gamboa

3I. "Inauguró el presidente el Museo de Artes Plásticas", en Excélsior, núm. I0995, tomo V, año XXXI, I9 de septiembre de 1947, pp. I y 9. "Alemán inauguró ayer el Museo de Artes Plásticas", en El Nacional, núm. 6644, tomo XXIV, año XVIII, viernes i9 de septiembre de 1947, 2a Sección, p. I.

32. Justo es aquella la época en México en que el Departamento Autónomo de Prensa y Publicidad regula, interna y externamente, todo cuanto del país se dice. Fundado en 1937 y en operación hasta diciembre de 1939, el DAPP es un tema poco estudiado, aunque uno se lo encuentra siempre al intentar desentrañar el origen, la percepción y el destino de las imágenes hechas por o para el gobierno en México entre 1930 y 1950. Véase Fernando Mejía Barquera, 
5. Sin catalogar, Bruselas, 1958 , Archivo Fernando Gamboa.

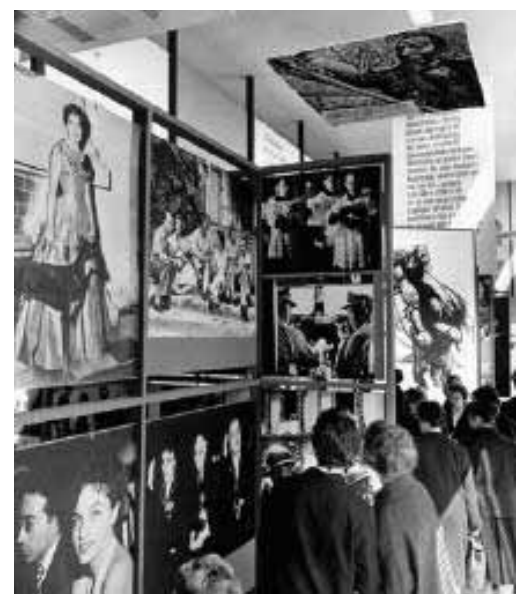

monta la Exposición Etnográfica donde todo había sido documentado desde la fotografía. Miguel Covarrubias actuó entonces como uno de sus asesores. La fotografía sólo acompañaba a las muestras de arte entre 1950 y I953, pero en la Exposición Universal de Bruselas en 1958 la fotografía es ya un género aparte y su lugar en el pabellón mexicano resulta indiscutible (fig. 5). ${ }^{33}$

En un texto escrito como homenaje póstumo a Miguel Covarrubias a treinta años de su muerte, en 1987, Fernando Gamboa lo califica así: “escenógrafo y museógrafo imaginativo, que intervino con su refinado gusto y sentido de las formas en la realización de importantes exposiciones". ${ }^{34} \mathrm{El}$ comentario de Gamboa señala que no había método o teoría alguna detrás de la labor de Covarrubias al exponer objetos de arte, sino, más bien, una capacidad intuitiva excelente para mostrarlos. Todo parece indicar que el estilo

El Departamento Autónomo de Prensa y Publicidad (1937-I939), en http://www.mexicanade comunicacion.com.mx/Tables/FMB/foromex/departamento.html URL, accesado el i de enero de 2005, I8:31, GMT.

33. Ramón Vargas Salguero, Pabellones y museos de Pedro Ramírez Vázquez, México, NoriegaLimusa, 1995, y Ana Garduño, "Candil de la calle, oscuridad de su casa. Un museo itinerante para el exterior”, en Revista Universidad de México, núm. 6I0, abril de 2002, pp. 68-73.

34. Lucía García Noriega y Nieto (coord.), Miguel Covarrubias. Homenaje, México, Centro Cultural Arte Contemporáneo (Fundación Cultural Televisa), Imprenta Madero, 1987, pp. I6-I7. 
de Miguel Covarrubias para exhibir colecciones o presentar eventos artísticos a un público tuvo cierta influencia en la práctica curatorial de Fernando Gamboa. Ambos tenían desarrollados proyectos de un currículum para museógrafos. Si bien una primera mirada al trabajo de Miguel Covarrubias sugiere que su enfoque al exhibir objetos tiene una intención contextualizante, derivada de sus preocupaciones antropológicas, es necesario también mirar su labor como escenógrafo y promotor de la danza para explorar otras vetas plásticas en su museografía.

Entre 1923 y 1936, el Chamaco Covarrubias vivió en Nueva York, sorprendiendo como caricaturista y cronista, haciendo "parodia ingeniosa" 35 del mundo del arte y la farándula desde Vanity Fair o The New Yorker. Fue allá donde Carl Van Vechten lo presentó con Frank Crowningshield, editor y cofundador del Museo de Arte Moderno de Nueva York, quien debió también ejercer alguna influencia en el sentido estético que Covarrubias adquirió y empleó después en su práctica museográfica. Covarrubias está rodeado aquí del frenesí exotista; ${ }^{36}$ ahí es donde Marlene Dietrich se despoja del disfraz de gorila y seduce con su fatal rubio platinado; ahí es donde King Kong trepó al rascacielos en busca del amor de Fay Wray o la muerte. ${ }^{37}$ Aquél es el Nueva York donde se revalora a Harlem y los twenties enloquecen con el jazz, algunas de cuyas escenografías para la Revue Negre fueron realizadas por Covarrubias las cuales también se vieron en París. Estuvo entre I93I y 1933 en Bali con la beca Guggenheim y visitó después, en 1939, Tehuantepec, el mismo lugar al que el secretario de Educación Vasconcelos recomendó ir a Diego Rivera en 1922; la "mera mata" del exotismo mexicanista. Covarrubias vuelve a México en 1942 y alterna, a partir de entonces, el trabajo para los teatros,

35. Bernard F. Reilly, jr., Caricaturas de Miguel Covarrubias, Nueva York, National Portrait Gallery, I984; trad. en Mercedes Benet, "Homenaje en Nueva York, olvido en México. Miguel Covarrubias", Sábado, núm. 382, primera plana y p. 2, suplemento de Unomásuno, núm. 2607, año VIII, 9 de febrero de 1985.

36. Carlos Monsiváis lo llama "mexicano doblemente exótico", en "Miguel Covarrubias: la caricatura de celebridades, el retrato de los pueblos", en Proceso. Semanario de Información y Análisis, núm. 425, 24 de diciembre de 1984, pp. 50-51. La nota está calcada de una entrevista hecha por Elena Poniatowska a Justino Fernández en México en la Cultura, núm. 426, $2^{\mathrm{a}}$ época, p. 6, suplemento de Novedades, núm. 5870, año XXII, I9 de mayo de 1957.

37. King Kong (1933). M. Cooper, guión y dirección; blanco y negro, Ioo min. RCA y RKo, EUA. Marlene Dietrich actúa el musical "Hot Vodoo", en la película Blonde Venus (1932), J. von Sternberg, blanco y negro, IO2 min., Paramount, EUA. 
su amateurismo - muy pronto profesionalizado - en la antropología y la promoción de la danza desde un puesto oficial. ${ }^{38}$ De hecho, para el ballet realiza sus trabajos más logrados como escenógrafo, con la simplicidad como rasgo característico. Grandes cortinas de fondo y unos cuantos trastos en primer plano; la acción que se desarrollaba o el objeto que se contemplaba quedaban aislados: "marcos poéticos a la manera de retablos populares", donde la perspectiva y la profundidad no existen. ${ }^{39}$ La estética de Covarrubias constituye así cierta unidad de acción, tiempo y lugar. No obstante su actitud antiacadémica, está claro que espera contextualizar dicha unidad sin dar una lección precisa de historia.

Teresa del Conde ha sugerido que los catálogos que documentan cada una de las exposiciones hechas por Gamboa estaban lejos de las convenciones requeridas y aceptadas para tales libros hoy en día. Es decir, que los cánones editoriales en el arte y la práctica curatorial en México evolucionaron en paralelo. No obstante los frecuentes cambios intempestivos que sufría el corpus de cada exposición, la diversidad de obras que viajaban al extranjero o eran reproducidas para tal efecto y la negociación constante con los coleccionistas o instituciones responsables de ellas, no hay contradicción que debilite el argumento de Gamboa sobre la coherencia plástica y espiritual del arte en México a lo largo de su historia. Acaso las fotografías y planos de los montajes o los libros que recogen aquellas exposiciones no ofrecen un camino sistematizado y fácil para acercarse a él. Padre fundador de la museografía en México y técnico de rasgos tan característicos que lo suyo es trabajo de curador ya en los cincuenta, Gamboa resuelve sus muestras de manera casuística: para cada problema, una solución inmediata y específica. Salvo las grandes obras de arte alrededor de las que cada exposición se articulaba (la Coatlicue en París, en 1952; una cabeza olmeca en Bruselas, en 1958, y un atlante en Nueva York, en 1964), ${ }^{40}$ cada obra menor es considerada en tanto que llena un espacio necesario en la mirada nacionalista e indigenista de la construc-

38. Miguel Covarrubias era director de Danza en el Instituto Nacional de Bellas Artes.

39. "Raoul Fournier, Carlos Solórzano y Justino Fernández hablan de Miguel Covarrubias", entrevista por Elena Poniatowska en México en la Cultura, núm. 426, p. 6, suplemento de Novedades, núm. 5870, año XXII, i9 de mayo de I957.

40. Veáse Ana Garduño, "Entre la modernidad y la tradición. Imágenes de un museo de arte mexicano para la exportación”, en Discurso Visual, revista electrónica del Cenidiap-INBA, núm. 6, primera época, enero-marzo de 2003, http: \discursovisual.cenart.gob.mx. 
ción espiritual implícita en el argumento repetido por Gamboa en sus exposiciones. La regla general de la mexicanidad en el arte se ilustra así mediante innumerables ejemplos específicos. Esta solución, atada a la disponibilidad inmediata de obras y a la circunstancia concreta de la política cultural en México, habla del poder como funcionario y de la celeridad con que dichos proyectos eran encargados al Jefe Gamboa. Nunca nadie había dispuesto, y ninguno volvería a hacerlo, de tan generosos presupuestos para promover el arte mexicano en el extranjero. La ineludible prisa o manera instantánea de la acción museográfica advierte cierta ausencia de trabajo teórico y ello induce otra vez a especular sobre sus cualidades más reconocidas y mencionadas: el "buen" gusto, una amplia cultura, la condición de connoisseur y su "ojo" para el arte.

Afirmo que el trabajo de Gamboa carece de estructura teórica, aunque no de un programa. Sostengo que no parece haber un sistema de pasos claros y sucesivos, seguido de un trabajo académico y una reflexión para ser enseñado; resulta clara solamente la consecución del argumento sobre el espíritu nacionalista transhistórico. Quiero rastrear, no obstante, las lecciones o influencias que Gamboa recibió alguna vez, para revelar con ellas el particular sentido del espacio, el "ojo" excepcional del museógrafo y demás maravillas incluidas en la mitología del Jefe. El diseño de instalaciones y la sintaxis de las piezas que Gamboa ordenaba para explicar el arte en México son una mezcla de narrativa histórica y preocupaciones estéticas. Si bien la naturaleza de la exposición como un medio es efímera, el bagaje heredado por Gamboa para hacer museografía se ha mantenido en México durante décadas. Algunas pistas que explicarían su trabajo y "escuela” curatorial están en su biografía intelectual: fue alumno de la Academia de San Carlos (él recuerda haber colgado los cuadros de la exposición anual de i916 ${ }^{4 \mathrm{I}}$ y misionero cultural en la década de los veinte; expuso la obra de las Escuelas al Aire Libre de Pintura y los reportes anuales de actividades de las escuelas rurales; más tarde se relacionó con la LEAR y también ahí montó conjuntos de cuadros (según reza el folleto de la época, él daría las clases de historia del arte fundado en el marxismo); asimismo, como se dijo al principio de estas notas, fue el responsable de una exhibición de grabado en España en 1937. Sin embargo, me 
atrevo a defender la relevancia de un discurso adaptado a la circunstancia mexicana y que Gamboa conservó entre sus papeles hasta su muerte en un fólder rotulado por él mismo: "Museografía y teoría". Se hallaba persuadido de que, más allá de la necesaria interacción espacial entre los objetos exhibidos y la arquitectura que los contenía, había una relación entre el público asistente y lo que cada grupo de objetos pretendía significar. El método del curador y museógrafo entonces no es solamente formal, pues cuenta también con un elemento metafísico. Gamboa propone a los mexicanos en particular reconocer su esencia una vez que enfrentan el arte de su nación; para los extranjeros y la humanidad en general la revelación es del gran arte universal en su modalidad mexicana. Aquel espíritu está ahí desde tiempos precolombinos y continúa hasta nuestros días.

Gamboa estaba seguramente al tanto del influyente trabajo de Alfred H. Barr en la muestra inaugural del Museo de Arte Moderno de Nueva York en 1929. Aquélla fue la primera vez que se vio un novedoso y modernista modo de exhibir obras de arte. Se trata de una manera de exponer objetos, mediante el aislamiento de éstos para que sean blanco de una contemplación estética; se los separa de su contexto original y se induce así cierta lectura unívoca. Barr intentó ubicar los objetos en soportes autónomos dentro de espacios neutrales que permitían una sola mirada y que convierten a aquéllos en obras de arte sin admitir adjetivos. Para relacionar conceptualmente hacían falta las cédulas y el argumento académico generalizador de la exposición en su conjunto. ${ }^{42}$ Cuando Gamboa montaba la exhibición The Art of José Guadalupe Posada en el Instituto de Arte de Chicago, en abril de I944, leyó con interés un artículo de Frederick J. Kiesler, que puso en sus manos Daniel Catton Rich, director de ese instituto, quien también le pasó el boletín de la American Association of Museums y un artículo sobre construcción de museos en Estados Unidos. ${ }^{43}$ Dicho artículo de 1942, titulado "Notes on Designing the Gallery", explica las conjeturas y convicciones de Kiesler sobre cómo el hombre primitivo no distinguía entre visión y realidad fáctica. ${ }^{44}$ En resumen,

42. Mary Anne Staniszewski, The Power of Display. A History of Exhibition Installations at the Museum of Modern Art, Cambridge-Londres, The MIT Press, 1998, pp. 6I-66.

43. Lawrence Vail, "Recent Museum Building Experience in the USA", The Museum Journal, vol. 47, marzo de 1948 (FG-97), pp. 22I-227.

44. El documento FG6 señala: "Today the framed painting on the wall has become a decorative cipher without life and meaning, or else, to the more susceptible observer, an object of 
refiere que cuando este sujeto ancestral pintaba en las cavernas o tallaba esculturas no había marco o soporte alguno para dicha ilustración del mundo que lo rodeaba. No había distancia entre la escena y su representación. La realidad y su copia no aparecían para el hombre primitivo como entidades o fenómenos separados y distintos. "Notes on Designing the Gallery" es un documento de una página jamás publicado y que se preservó en los archivos del legado Kiesler. ${ }^{45}$ Pero Gamboa tuvo siempre consigo el documento en su oficina. ${ }^{46}$ Kiesler defendía su idea de la "unidad primordial", teorizando que la obra de arte que reconocemos actualmente en aquellas cuevas y tallas tenían una función activa, es decir, se trataba de factores orgánicos de la vida humana, no de una liminalidad estética o de mercancías. En otras palabras, el arte era a la vez sagrado y social, el arte era evento para la veneración y eje de la vida en comunidad. Carecía de un lugar más allá de estas funciones concretas en la cotidianidad de las tribus primigenias. Esa elaboración es similar al concepto de arte que estetas e historiadores contemporáneos de Gamboa hacían sobre el pasado mexicano. Entre otros, Justino Fernández a propósito de la Coatlicue y Miguel Covarrubias con sus esquemas iconográficos para ubicar a la cultura olmeca. ${ }^{47}$ También la actitud política de Kiesler hace eco de la de Gamboa, pues su corpus ideológico en términos de la actividad profesional es idéntico: donde Kiesler habla de un "técnico arquitectural”, Gamboa y sus compañeros de la LEAR prefieren describirse como "trabajadores". Ambos rechazarán las definiciones de "intelectual” o "artista" justamente como un manifiesto político abierto.

interest existing in a world distinct from his. Its frame is at once symbol and agent of an artificial duality of 'vision' and 'reality' or 'image' and 'environment', a plastic barrier across which man looks from the world he inhabits to the alien world in which the work of art has its being. That barrier must be dissolved: the frame, today reduced to an arbitrary rigidity, must regain its architectural spatial significance”, Frederick Kiesler, 1942. Una transcripción se encuentra también en www.arch.mcgill.ca/prof/mellin/arch67i/winter20oI/dkouba/drm/ kiesler.htm, URL accesado el 2 de febrero de 2004, I9:I9, GMT.

45. Kiesler, "Notes on Designing the Gallery", manuscrito inédito citado por Melvin Lader, "Peggy Guggenheim's Art of this Century: The Surrealist Milieu and the American AvantGarde, I942-I947", tesis de doctorado, Delaware, University of Delaware, I98I, p. II4. 46. FG6, una página mecanografiada.

47. Justino Fernández, Estética del arte mexicano: Coatlicue, el retablo de los Reyes, el hombre, México, Universidad Nacional Autónoma de México, 1972, y Miguel Covarrubias, Origen y desarrollo del estilo artístico olmeca, México, Sociedad Mexicana de Antropología, 1942 (reuniones de la mesa redonda, Mayas y olmecas), pp. 46-49. 
En otro artículo, del que Gamboa se preocupó por obtener y conservar una copia, un autor no identificado reseña el trabajo de Kiesler para Art of this Century. ${ }^{48}$ Aquélla fue la exposición que presentó la colección de obras de arte propiedad de Peggy Guggenheim, inaugurada el 20 de octubre de 1942 en la East $57^{\text {th }}$ de Nueva York. ${ }^{49}$ Kiesler había estado trabajando como director del Laboratorio de la Escuela de Arquitectura de la Universidad de Columbia entre 1937 y 1942. Fue ahí cuando desarrolló su teoría de "la correlación y el diseño", donde las exposiciones o escaparates - ya fueran para el museo o el comercio, empezando con Art of this Century - se ajustarían al método conocido entonces como "exhibición espacial”, que proponía seguir cuatro principios fundamentales. Para empezar, Kiesler quería que toda instalación fuera "móvil y desmontable", es decir temporal, aunque de ninguna manera provisional o carente de cualidades estéticas. El siguiente asunto que ocupaba a Kiesler era el económico; los displays y su construcción obedecerían la "ley de prioridades": un mínimo de gastos, como si la mano de obra escaseara, y una gerencia de la galería lo menos problemática posible. En tercer lugar, la iluminación y el soporte: aquélla habría de ser indirecta y en éste todo marco debía eliminarse. Las luces debían relacionarse, por su intensidad y color, con la pintura de los muros dentro del museo o galería. Finalmente, el problema de la fatiga, la comodidad y el tránsito de los visitantes debía también tomarse en cuenta. ${ }^{50} \mathrm{Al}$ final del artículo antes citado, el autor comenta: "estas galerías son el resultado de una espléndida cooperación entre los trabajadores, el dueño y el diseñador". ${ }^{\mathrm{I}}$

Kiesler dejó Alemania antes de que sus contemporáneos tuvieran que huir de Hitler. Fue amigo de toda la vida de Theo van Doesburg y su rival en el ajedrez durante el aislamiento que prefería Marcel Duchamp. La suya había sido una carrera muy productiva y variada. Participó en De Stijl, haciendo

48. Documentos foliados FG4 y 5, s.d., Archivo Fernando Gamboa.

49. Peggy Guggenheim, Confesiones de una adicta al arte (Confessions of an Art Addict, 1960), trad. de D. Aguirre, pról. de Gore Vidal, intr. de Alfred H. Barr, Barcelona, Lumen, 2002 (Palabra en el Tiempo, 319), pp. 87-89.

50. Frederick Kiesler, Contemporary Art Applied to the Store and Its Display, Nueva York, Brentano's Publishers, I930; "Murals Without Walls", Art Front, I8 de diciembre de 1936, "New Display Techniques for Art of This Century", Architectural Forum, LXXVIII, febrero de 1943, "Trends in Exhibitions", Partisan Review, invierno de 1946, "The Art of Architecture for Art”, Art News 56, núm. 6, octubre de 1957.

5I. Documento foliado FG222, s.d., Archivo Fernando Gamboa [la traducción es mía]. 
diseños para teatros y galerías de arte. Kiesler también conoció a los surrealistas y trabajó con ellos en Nueva York en 1940. A pesar de estar comprometido con la política de izquierda, Kiesler teorizaba que era necesario explorar y explotar el aparador comercial como un medio nuevo. Las ideas de Kiesler respecto al diseño y la arquitectura se conocieron primero a principios de los treinta, cuando publicó Contemporary Art Applied to the Store and its Display $^{52}$ y antes de 1950 con sus largos manifiestos "correlacionistas" contestatarios de la influencia de Mies van der Rohe y Le Corbusier, titulados Pseudofuncionalismo en la arquitectura moderna. El concepto fundamental para acercarse a Kiesler es justamente el de la "correlación": una compleja interacción entre los objetos, las personas que los aprehenden, el espacio donde esta relación se lleva a cabo y la ideología que la informa. Definición tan ambigua y amplia podría ser también la de "cultura". Pero Kiesler propone un apunte adicional para entender lo que "correlación” significa. Más allá de la kinésica (el estudio de las relaciones espaciales entre objetos) y la proxémica (la semántica cultural implícita en la cercanía y las relaciones espaciales de las personas con los objetos), la correlación presupone una fuerza interior o espíritu propio de las cosas que se comparte al ser sensibles los espectadores al gran "arte" allí contenido. ${ }^{53} \mathrm{El}$ término "correlación" fue explicado por Kiesler en I939 como una exploración de los modos en que el hombre, la naturaleza y la tecnología se imbrican. ${ }^{54}$ Aunque en apariencia oscuro y expresado mediante una jerga más bien esotérica, el objetivo último de Kiesler es claro: el arte debía buscar el cambio social real, sin alejarse del museo y explotando la nueva veta plástica ofrecida por el escaparate comercial.55

52. Melvin Lader, op. cit. Christoph Greunenberg, "Espaces spectaculaires: l'art de l'installation selon Frederick Kiesler", en Béret, Frederick Kiesler, pp. IO3-I13.

53. Andrew Otwell, "Frederick Kiesler as a Commercial Designer", I997 (URL accesado el 6 de junio de 2004, Ir:OI, GMT), www.heyotwell.com/work/arthistory/KielserDesign.html, tesis de maestría para el Departmento de Historia del Arte en la Universidad de Texas en Austin.

54. Kiesler, "On Correalism and Biotechnique: A Definition and Test of a New Approach to Building Design”, Architectural Record 86, núm. 9, septiembre de 1939, pp. 6I y ss.

55. Entre los libros conservados en la biblioteca personal de Fernando Gamboa están varios reportes anuales de premios a escaparates y estrategias publicitarias editadas por organismos de mercadotecnia en Estados Unidos e Inglaterra. FG2204 y FG2205, F. A. Mercer y W. Gaunt (eds.), Modern Publicity 1939-1940, Londres y Nueva York, I941; Annual of Art and Industry, Studio, Inglaterra, I94I. 
Desde que dejó Europa, Kiesler había estado especulando a partir de la noción del Gesamtkunstwerk. ${ }^{56} \mathrm{Su}$ intención fundamental era hallar un espacio unificado para la hechura del arte, su expresión y su estudio. Las ideas de Kiesler al respecto en aquella época fueron a menudo adjetivadas por él mismo como "interminables o sin fin". Ello significaba no sólo que un objeto debía cubrir varias funciones (como recomendaba la Bauhaus), sino también constituirse en la obra de arte última, en una creación total. Pero lo "sin fin o interminable" implicaba también una toma de posición política muy clara: es la enunciación de un programa, sin importar las desviaciones metafísicas a que podría llevar el peculiar vocabulario de Kiesler. Se trata de construir una visión social y estética según la cual el arte y la educación llegarían a ser herramientas útiles para el cambio en su sociedad dejando de lado los prejuicios contra el capital. En el caso de Gamboa, la noción resulta relevante cuando en su discurso curatorial la narrativa histórica es multirreferencial en cuanto al espíritu mexicano sin obstar las coordenadas espaciotemporales. Si la reunión de obras de arte de Gamboa o Covarrubias es la dramatización o puesta en escena de algo más (la mexicanidad, la nación, el espíritu) que sirve al Estado, ello los obliga entonces a una elocuencia tal que pasado y presente se vean atrapados o contenidos en una elipse. De este modo, lo "interminable o sin fin" se evidencia otra vez. El supuesto teórico debió ser agradable para Gamboa y su particular ethos, puesto que encajaba perfectamente con el postulado mexicanista a través del tiempo. Los mexicanos con formación universitaria de la época, como Gamboa, entusiastas del vasconcelismo, creían que el trabajo creativo e intelectual tenía en sí mismo un valor redentor para las masas.

El tema específico que Gamboa escoge para probar su elipse histórico-artística es el de la pretendida relación sardónico-cotidiana que los mexicanos han tenido siempre con la muerte y su representación. Así están pensadas las exposiciones; ésa y la de la indianidad son las figuras repetidas; el énfasis que se pone en ellas resulta claro en todas las exposiciones. La generalización no es mía, es de la época, es de México en 1950. Ésa es la versión oficial que explica el arte mexicano. Así, cuando Gamboa se refería al arte universal,

56. La escuela de la Bauhaus — de la que Kiesler fue alumno en 193I- buscaba la "obra de arte total”; sus teóricos eran W. Kandinsky y W. Gropius. Para conocer una explicación fácil sobre el término, véase www.bauhaus.de/english/bauhausı9I9/ uRL accesado el 2 de febrero de 2004, I9:33, GMT. 
implicaba también que "el innegable triunfo de la pintura mexicana en la Bienal de Venecia" demostraba que aquí se practicaba la más vieja y más actual forma del arte: aquella cuya función esencial es social. ${ }^{77}$ Gamboa llama a esta utilidad y origen sociales del arte un modo de ser "realista". Durante la entrevista que condujera Margarita T. de Ponce y que Gamboa, "el joven y dinámico subdirector del Instituto Nacional de Bellas Artes", tenía preparada con antelación, el curador cita a Jean Pierre, del Séminaire des Lettres Françaises, y a Rodolfo Paluchini, organizador de la XXV Bienal de Venecia. ${ }^{58}$ Son los europeos, y Gamboa lo demuestra con recortes de periódico que tenía consigo para la ocasión, quienes hallan la coherencia "subversiva y perturbadora" en el arte de los aztecas, Rivera, Orozco, Siqueiros y Tamayo. Pero el autor de aquella versión de mexicanidad que se revela a los académicos de Francia e Italia es Fernando Gamboa. Entre quienes prestaron obra para esta exposición, además del Museo de Bellas Artes, figuraron Miguel Covarrubias, Vicente Lombardo Toledano e Ignacio Bernal.59

Esta versión oficial promovida por la delegación mexicana fue adoptada sin crítica por historiadores del arte extranjeros, periodistas y público asistente. ${ }^{60}$ En todas estas opiniones el tema elucidado con la muestra de arte mexicano era la peculiar relación que desde siempre habían tenido los mexicanos con la muerte. ${ }^{61}$ Jean Cassou señala, por ejemplo, esculturas aztecas, gráfica decimonónica y obras posteriores a la Revolución que demuestran "sarcásticas meditaciones sobre la muerte". ${ }^{62}$ La exposición de Arte Mexicano, Antiguo y Moderno en París dio a conocer, durante la primavera de 1952, más

57. Excélsior, 16 de julio de 1950, p. 9, recorte del periódico conservado como documento con el folio FG446Tt, Archivo Fernando Gamboa.

58. 13 de julio de 1950, "Cuatro pintores mexicanos triunfan ante 832 artistas de 22 países", cuatro páginas mecanografiadas FG45ITT a FG455TT.

59. Documentos foliados FG246-248 zz, Archivo Fernando Gamboa.

6o. Manuel Tello, vicecanciller; Carlos Chávez, director del Instituto Nacional de Bellas Artes. FG864TT 2 p. (New York Herald Tribune, Pedro Carney, s.d., june 2 $2^{\text {nd }}$, I952, "Mexican Art Through the Ages"; Robert Sevard, "35 siècles d'art au Mexique", Combat, june 2 ${ }^{\text {nd }}$, I952; Joseph Pichard, "L' Art Mexicain á Paris", La Croix, june $9^{\text {th }}$, 1952).

6I. Interesantes críticas a esta generalización se encuentran en la obra de Claudio Lomnitz Adler, Deep Mexico, Silent Mexico, University of Minnesotta, 2003, y en el libro San Pascualito Rey y el culto a la muerte en Chiapas, de Carlos Navarrete, México, Universidad Nacional Autónoma de México-Instituto de Investigaciones Antropológicas, 1982.

62. Jean Cassou, "20 siglos de arte mexicano", El Universal, México, 2 de junio de 1952, pp. I-5, recorte del periódico conservado como documento sin folio, Archivo Fernando Gamboa. 


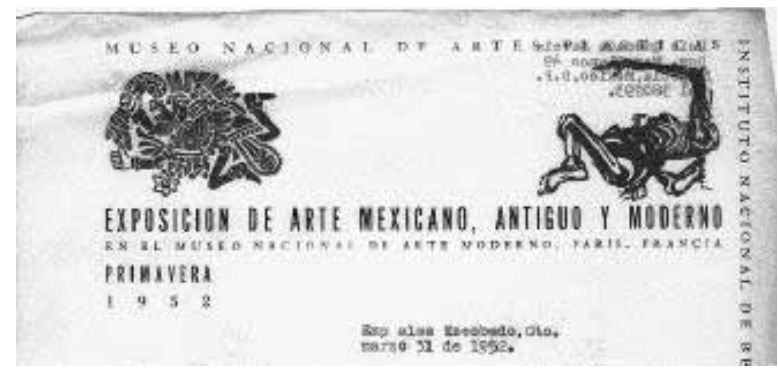

6. Archivo Fernando Gamboa.

de cincuenta boletines, escritos por académicos y especialistas, que explicaban diversas secciones y temas de la muestra. Dichos documentos estaban impresos en papel membretado del Museo Nacional de Artes Plásticas, el Instituto Nacional de Bellas Artes y la Secretaría de Educación Pública. En cada margen superior dos figuras adornaban la página: un Mictlantecuhtli, o "señor de la muerte" entre los antiguos mexicanos, y un cadáver o figura yacente, tomado de la obra de José Clemente Orozco (fig. 6). El diseño gráfico hizo de la papelería oficial una insistencia más sobre la idiosincrasia mexicana en tiempos remotos y actuales. El boletín número I, firmado por Paul Westheim, se titulaba Orígenes y particularidades del arte precolombino mexicano y el México moderno. ${ }^{63} \mathrm{La}$ función principal del arte, su raison d'être, dice Westheim, es la interpretación del mito. La vida toda de la comunidad, la existencia misma de todos y cada uno de sus individuos se explicaba en estrictos términos de la deidad y su creencia. Ahí no había diferencia alguna entre el hecho y su representación, como decía Kiesler. La creación artística dependía de la exaltación religiosa. Citando a George Vaillant, Westheim añade que la noción de "bellas artes" no existía entre los aztecas; usará también el esquema empleado por Worringer sobre el estilo gótico como la expresión de un carácter metafísico para analizar la escultura prehispánica. ${ }^{64}$

63. Documento FG75-76ww 2 p., original en francés [la traducción es mía].

64. Justo en esa época, Mariana Frenk, esposa de Westheim, traducía al español la obra de Wilhelm Worringer, Form in Gothic; un poco después apareció otro libro de Worringer, Abstracción y naturaleza, México, Fondo de Cultura Económica, 1953. 
Jean Cassou era el conservador del Museo de Arte Moderno de París. En un artículo escrito por él y traducido al español para su publicación en México y Francia al mismo tiempo, ${ }^{65}$ refiere un "México universal [...] un país que ha preservado su identidad [donde] todo el arte es naïf y primitivo". Añade incluso que los frescos de Orozco, Rivera y Siqueiros no son trabajos ordenados por "la corte" (el gobierno mexicano), que no son oficiales puesto que la impronta popular que revelan ha sido la misma ahí desde hace veinte siglos. En el mismo tenor, Paul Rivet - director del Museo del Hombrediría en una nota redactada para la revista L'Observateur que los mexicanos están acostumbrados a lo "mórbido", "cruel" y "macabro". Estos adjetivos, advertía, fueron recogidos durante la exposición, son reacciones de los visitantes frente a las obras de arte. ${ }^{66}$ Debo advertir que exploro aquí la consecución del argumento, no los sofismas a los que recurre.

Sin detenernos demasiado en vericuetos lógico-discursivos, es observable cierta coherencia en el modo en que lo curatorial se lleva a cabo. Podría defenderse que aquella versión de mexicanidad e ironía ante la muerte era una construcción realizada por extranjeros y solamente adaptada a la conveniencia de los mexicanos. La película de Sergei Eisenstein ;Que viva México!, de I93I, se basa justamente en el tropo de la muerte y la risa para contar su historia en episodios; el libro Ídolos detrás de los altares de Anita Brenner, publicado en 1929, argumenta que la religiosidad de los mexicanos y la representación escapan a su ubicación en etapas históricas claras; fue Jean Charlot quien amonestó a los artistas mexicanos sobre la relevancia de Posada, y Paul Westheim quien explica su relación con Holbein y la danza de la muerte. ${ }^{67}$ Lo innegable es que aun si esta versión de mexicanidad y su representación eran construidas y revisadas por académicos nacionales (el Instituto de Inves-

65. Jean Cassou colaboró también con Jean Avalon, director de Aesculape. The Illustrated Magazine of Arts and Literature in their Contribution to Science and Medicin (FG-266LL, I5 Pp.), núms. 7-8 (número especial), año 33, nueva época, París, julio-agosto de I952, pp. I45-I68, 24 fotografías de Gisèle Freund.

66. Paul Rivet, "Signification du succés de l'art Mexicain”, L'Observateur, núm. II2, 2 de julio de 1952, p. I9.

67. Eisenstein, ¡Que viva México! (193I), blanco y negro, EUA-México, $90 \mathrm{~min}$, U. Sinclair prod.; Anita Brenner, Idols Behind Altars, Nueva York, Payson \& Clarke, I929; Paul Westheim, La calavera, Librería Robredo, I953, trad. M. Frenk y Jean Charlot, "Mexico of the Poor”, Mexican Life, marzo de 1926 (1922, trad. de Diego Rivera). 
DOI: http://dx.doi.org/10.22201/iie.18703062e.2005.87.2194

FERNANDO GAMBOA Y SU VERSIÓN DE MÉXICO

tigaciones Estéticas se funda en 1939, la carrera de museografía se organiza en la Escuela Nacional de Antropología en 1942-I943 y Justino Fernández publica su Estética del arte mexicano: Coatlicue, el retablo de los Reyes, el hombre en I954), dicho sistema de creencias sobre lo mexicano y el arte es repetido por todos, pero solamente Gamboa - y Covarrubias, hasta su prematura muerte en 1957 - tornan esa narrativa en arreglos y soluciones curatoriales. \$ 